\title{
Influence of Modifying Mixtures on Si Crystal Formation in Al-7\%Si Alloy
}

\author{
Anna Zykova ${ }^{1}$, Lyudmila Kazantseva ${ }^{2}$ (D), Natalya Popova ${ }^{3}$, Alexander Vorozhtsov ${ }^{2}$ \\ and Irina Kurzina ${ }^{2, *}$ \\ 1 School of Core Engineering Education, National Research Tomsk Polytechnic University, \\ 634050 Tomsk, Russian; zykovaap@mail.ru \\ 2 Chemical Faculty and Laboratory of High-Energy and Special Materials, National Research Tomsk State \\ University, 634050 Tomsk, Russian; kazantseva2911@mail.ru (L.K.); abv1953@mail.ru (A.V.) \\ 3 Department of Physics, Tomsk State University of Architecture and Building, 634003 Tomsk, Russian; \\ natalya-popova-44@mail.ru \\ * Correspondence: kurzina99@mail.ru; Tel.: +7-913-882-10-28
}

Received: 8 December 2017; Accepted: 25 January 2018; Published: 30 January 2018

\begin{abstract}
Using scanning and transmission electron microscopy, we studied silicon particles formed during the solidification of $\mathrm{Al}-7 \% \mathrm{Si}$ alloy when different modifying mixtures were introduced into the melt: (1) a mixture of ultrafine powders $\mathrm{Na}_{3} \mathrm{AlF}_{6}+\mathrm{K}_{2} \mathrm{ZrF}_{6}+\mathrm{TiO}_{2}+\mathrm{ZrO}_{2} ;(2) \mathrm{K}_{2} \mathrm{ZrF}_{6}$; and (3) the flux Arsal. By differential scanning calorimetry, it was established that modifying mixtures significantly influenced the temperature of the solidification processes. The formation of two types of Si crystals was established. The first type of Si crystals precipitated during the solidification of the eutectic mixture $(\alpha-\mathrm{Al}+\mathrm{Si})$ in the form of needles or plates. The second type of $\mathrm{Si}$ crystals was segregated from eutectic Al-phases or segregated from the solid phase $\alpha$-Al upon cooling in the solid state. The introduction of modifiers led to a shift in solidification temperatures. When fluoride salts were used, there was an increase in the temperature of eutectic solidification. Silicon crystals were large (up to $10 \mu \mathrm{m}$ ), with a local excess of aluminum concentration.
\end{abstract}

Keywords: Al-7\%Si alloy; modification; ultrafine powders; fine structure; phase composition

\section{Introduction}

Cast alloys of the Al-Si system are widely used as modern structural materials in the aircraft and automotive industries, among others, owing to their high specific strength, high resistance to dynamic loads, and low cost [1]. Nevertheless, their extensive use in industry is often restricted by the presence of coarse-crystalline structures in alloys that consist of a $\alpha$-Al solid solution and eutectic phases $(\alpha-\mathrm{Al}+\mathrm{Si})$. It is known that the structure of the alloy formed accounts for strength characteristics and plasticity of silumins. In this regard, the morphology of the silicon crystals formed during eutectic crystallization and segregation from the solid solution of melts has a particular impact on the operational characteristics of the alloy.

A widely used method of influencing the microstructure of silicon precipitations in Al-Si alloys is the modification by ultrafine particles of compounds of rare-earth and refractory metals [2-7]. In this article, it is shown that the introduction of modifiers leads to a change in the temperatures of basic solidification processes and, accordingly, the morphology of basic structural-phase component materials. At present, a sufficiently large volume of experimental data on the use of metal oxides $\left(\gamma-\mathrm{Al}_{2} \mathrm{O}_{3}, \mathrm{Al}_{2} \mathrm{O}_{3}, \mathrm{TiO}_{2}, \mathrm{ZrO}_{2}, \mathrm{SrO}\right)$, carbides ( $\left.\mathrm{TiCN}\right)$, borides (Nb-B, Ti-B), carbon-bearing materials $\left(\mathrm{BaCO}_{3}, \mathrm{C}\right)$, and their mixtures has been accumulated for modification of the microstructure of primary matrix grains, the eutectic mixture, and precipitations of secondary phases of Al-Si alloys [8-14]. However, the literature presents ambiguous data on the influence of metal oxides on the microstructure 
of aluminum-silicon alloys. In References [8-14], it was demonstrated that when modifying mixtures are used, one can observe the refinement of $\alpha$-Al dendrites, their more uniform distribution, and refinement and change in the morphology of Si crystals in the eutectic mixture, which in turn enables the enhancement of mechanical properties. In Reference [15], the authors explain the influence of $\mathrm{P}$ and $\mathrm{Sr}$ on the various morphologies of Si particles in alloys of the Al-7\%Si type. The Si nucleates on the AlP but grows on the oxide substrate to develop a coarse plate-like morphology. After Sr addition, bifilms are no longer sequestered into primary Si particles, therefore remaining in suspension in the melt, available for blocking interdendritic and intergranular flow and providing the mechanism (by unfurling and inflating) for the initiation of porosity. The observed zero permeability of the solidifying dendrite mesh is proposed to be the result of the presence of bifilms. These will be rigidized by (i) the increased numbers and thickness of the oxide films because of the greater reactivity conferred by $\mathrm{Sr}$, (ii) increased thickness of dams because of pileups if the melt treatment has been particularly poor, and (iii) partial inflation by hydrogen gas (if any). In Reference [16], the results of reducing the silicon particle size to a submicron level in an aluminum-silicon alloy using a powder metallurgy process are presented. It was shown that the fine silicon particles with an average diameter of approximately $20 \mathrm{~nm}$ were dispersed in the $\mathrm{Al}$ matrix of a hypereutectic $\mathrm{Al}-\mathrm{Si}$ alloy powder produced by the spinning water atomization process. This powder was sintered at $623-773 \mathrm{~K}$ for a maximum of $20.4 \mathrm{ks}$. The silicon particles became larger during sintering, but their size remained at a submicron level. It was also shown that the silicon particle size influenced the Vickers hardness of the alloy; the values of the Vickers hardness test were two to three times those of conventionally cast bars of the same alloy. The most effective method was the use of refractory metal oxides as modifying mixtures. In Reference [9], the nanoparticles of $\mathrm{Al}_{2} \mathrm{O}_{3}, \mathrm{TiO}_{2}$, and $\mathrm{ZrO}_{2}$ were used to modify Al-Si alloys. In the course of such modification, the refinement of structural components and enhancement of mechanical properties (strength, unit elongation, and hardness) by $2 \%$ took place when introducing $\mathrm{Al}_{2} \mathrm{O}_{3}$ and by $3 \%$ when using $\mathrm{TiO}_{2}$ and $\mathrm{ZrO}_{2}$. However, there was no analysis of the experimental data obtained regarding the influence of the modified mixture introduced on the dendrite structure of silicon and on mechanical properties.

Earlier it was demonstrated [17] that introducing a modifying mixture of $\mathrm{Na}_{3} \mathrm{AlF}_{6}+\mathrm{K}_{2} \mathrm{ZrF}_{6}+\mathrm{TiO}_{2}$ $+\mathrm{ZrO}_{2}$ into an Al-Si melt resulted in the uniform distribution of the eutectic $(\alpha-\mathrm{Al}+\mathrm{Si})$ and, on average, the size of silicon crystals was reduced 1.5 times and the shape of Fe-bearing phases underwent refinement and changes, as compared to the initial unmodified alloy, occur. However, the solidification processes were not considered in detail, and the relationship between the nature of the modifiers introduced and the structure of precipitating phases was not revealed. The study of morphological characteristics of silicon crystals precipitated in the course of Al-Si solidification is relevant; because structural characteristics of silicon substantially influence the operational characteristics of the material, the study of the influence of the modifying mixtures on the properties and morphology of precipitated silicon crystals is urgent. In this paper, the results of the study of the influence of a modifying mixture based on $\mathrm{Na}_{3} \mathrm{AlF}_{6}+\mathrm{K}_{2} \mathrm{ZrF}_{6}+\mathrm{TiO}_{2}+\mathrm{ZrO}_{2}$ on the morphology of Si particles in the Al-7\%Si alloy are presented. The comparative data on the influence of the commercial $\mathrm{K}_{2} \mathrm{ZrF}_{6}$ and Arsal 2120 [18] fluxes on the morphology of precipitated silicon in the $\mathrm{Al}-7 \% \mathrm{Si}$ alloy are provided.

\section{Materials and Methods}

Ultrafine powders (UFP) with an average particle size of $d_{a v}=0.7 \mu \mathrm{m}$ and in the amount of 0.4 mass. \%, composed of $\mathrm{Na}_{3} \mathrm{AlF}_{6}+\mathrm{K}_{2} \mathrm{ZrF}_{6}+\mathrm{TiO}_{2}+\mathrm{ZrO}_{2}$ [19], were used as a modifying mixture (MM). The morphological characteristics of the precipitated silicon grains were investigated due to the introduction of 0.4 mass. \% UFP of refractory oxides into the Al-7\%Si melt. The amount of modifier added ( 0.4 mass. \%) is optimal and determined theoretically and experimentally. Comparative studies of the structure of precipitated silicon particles were conducted with the use of the modifiers based on solely fluoride-containing salts: $\mathrm{K}_{2} \mathrm{ZrF}_{6}$ used in industry (in the amount of 0.2 mass. \%) and the flux Arsal 2120 (in the amount of 0.2 mass. \% of the following composition, mass. \%: 20.9 O; $20.2 \mathrm{Cl}$; 
19.8 F; 18.8 Na; $14.4 \mathrm{~K} ; 2.9 \mathrm{~S} ; 2.3 \mathrm{Si} ; 0.4 \mathrm{Mg} ; 0.1 \mathrm{Al} ; 0.1 \mathrm{Ca}$; 0.03 Cr; 0.04 Br; 0.02 Fe; $0.01 \mathrm{P}$ ). The ratio of 0.2 mass. \% was determined for the modifying salts in industrial melting conditions and is optimal for the formation of the necessary structure in the alloy.

Melting was conducted in CAT- 0.25 furnaces (JSC "Inductor SPb", St. Petersburg, Russia) in steel crucibles according to the technology adopted at the foundry. We used aluminum of the A7-grade as initial charge materials. To speed up melting, first the furnace was heated to $800{ }^{\circ} \mathrm{C}$, then a steel crucible with the batch load was placed into the furnace. After the silumin melted, the crucible was withdrawn from the furnace and the melt's mirror was cleaned of the oxide film; then the modifying mixture was introduced. Modifying mixtures were introduced into the silumin melts under the cap, which was made of stainless steel. In order to distribute the modifying mixture throughout the whole volume of the melt, the cap was moved over the whole area of the melt until the entire sample was completely melted. After the introduction of modifying mixtures, the melt was soaked in the furnace at a temperature of $800^{\circ} \mathrm{C}$ for $120 \mathrm{~min}$. The samples intended for mechanical testing were cast in chills. Thermal treatment was carried out in accordance with mode $\mathrm{T} 2$ (Russian standard) at a temperature of $300{ }^{\circ} \mathrm{C}$ [20].

The microstructure of alloys, phase localization, and the defect structure were studied by the methods of scanning electron microscopy (SEM, an electron microscope Vega II LMU, (TESCAN, Brno, Czech Republic) along with the system of X-ray energy-dispersive microanalysis INCAEnergy 350 (Oxford Instruments, High Wycombe, UK) and transmission electron microscopy (TEM, a JEM-2100F microscope, JEOL Ltd., Tokyo, Japan). Differential scanning calorimetry (DSC, thermoanalyzer SDT Q600, TA Instruments, New Castle, DE USA) was conducted at a heating $/$ cooling rate of $10^{\circ} \mathrm{C} / \mathrm{min}$.

\section{Results}

According to the phase diagram of $\mathrm{Al}-\mathrm{Si}$, in the course of cooling of the melt of a hypoeutectic composition, the liquid becomes saturated toward a solid phase and primary solidification of the $\alpha$-Al phase occurs. By the end of primary solidification, the liquid solution is enriched by silicon. Solidification of the $\alpha$-phase finishes in the alloy, and the second stage begins-namely, the solidification of the melt of the eutectic composition. At the eutectic temperature, all of the liquid solidifies and the alloy consists of primary crystals of the $\alpha$-phase and the eutectic mixture based on $\alpha-\mathrm{Al}$ and $\mathrm{Si}$, localized between matrix grains of $\alpha$-Al. Then, on cooling, phase transformations in the solid state occur. When the temperature is decreased, silicon crystals (a solid aluminum solution in silicon of the variable composition) precipitate from $\alpha$-Al crystals. Earlier in the published manuscript [17], the XRD results were presented. According to the XRD data, the samples contained melt $\alpha$-Al, containing phases $\beta-\mathrm{Si}, \alpha-\left(\mathrm{Al}_{2} \mathrm{FeSi}\right)$ and $\beta-\left(\mathrm{Al}_{5} \mathrm{FeSi}\right)$. The $\mathrm{XRD}$ results are confirmed by SEM studies, according to which phases $\alpha-\left(\mathrm{Al}_{2} \mathrm{FeSi}\right)$ and $\beta$ - $\left(\mathrm{Al}_{5} \mathrm{FeSi}\right)$ are clearly seen in the mode of electron backscattering. In addition, we performed XREDM when recording SEM in local points of different phases and calculated a theoretical chemical composition, which corresponds to the XRD data.

Figure 1 shows SEM images of the Al-7\%Si alloy supplemented with modifying mixtures of a different chemical composition from that of the unmodified sample. According to the SEM data, silicon that precipitated in the eutectic composition in the initial Al-7\%Si alloy (without the introduction of MM) was characterized by a needle- and/or plate-like texture and uneven distribution. Nonuniform distribution and local accumulation of eutectic mixture $(\alpha-\mathrm{Al}+\mathrm{Si})$ were observed in the melt in some areas in Figure 1a. The size of silicon particles in the eutectic mixture was from $\sim 2.5$ to $\sim 64 \mu \mathrm{m}$, and the average size of particles was $\sim 12.5 \mu \mathrm{m}$ in Figure $1 \mathrm{~b}$.

According to the TEM data, in the initial state of the $\mathrm{Al}-7 \% \mathrm{Si}$ alloy, within the $\alpha-\mathrm{Al}$ grain, there were Si particles of $0.07 \mu \mathrm{m}$ in the form of chains (Figure 2a, marked by arrows). Colonies of silicon particles (virtually a Si phase) were located inside the grain chaotically at a distance between particles of up to $0.03 \mu \mathrm{m}$. When the structure was investigated by the TEM method, it was discovered that the particles of the eutectic and Si grains segregated from the solid solution had a defect-free structure. This was confirmed by the absence of dislocations in silicon particles by the results of TEM studies (Figure 2). 


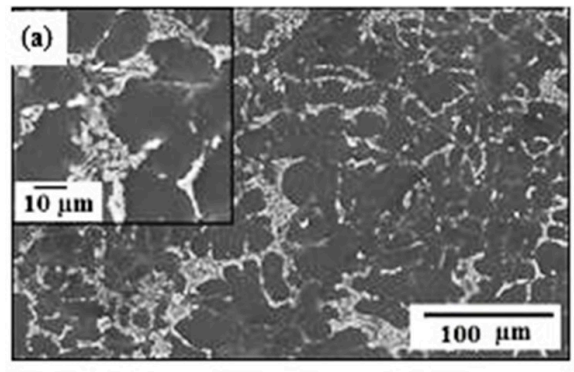

(b)
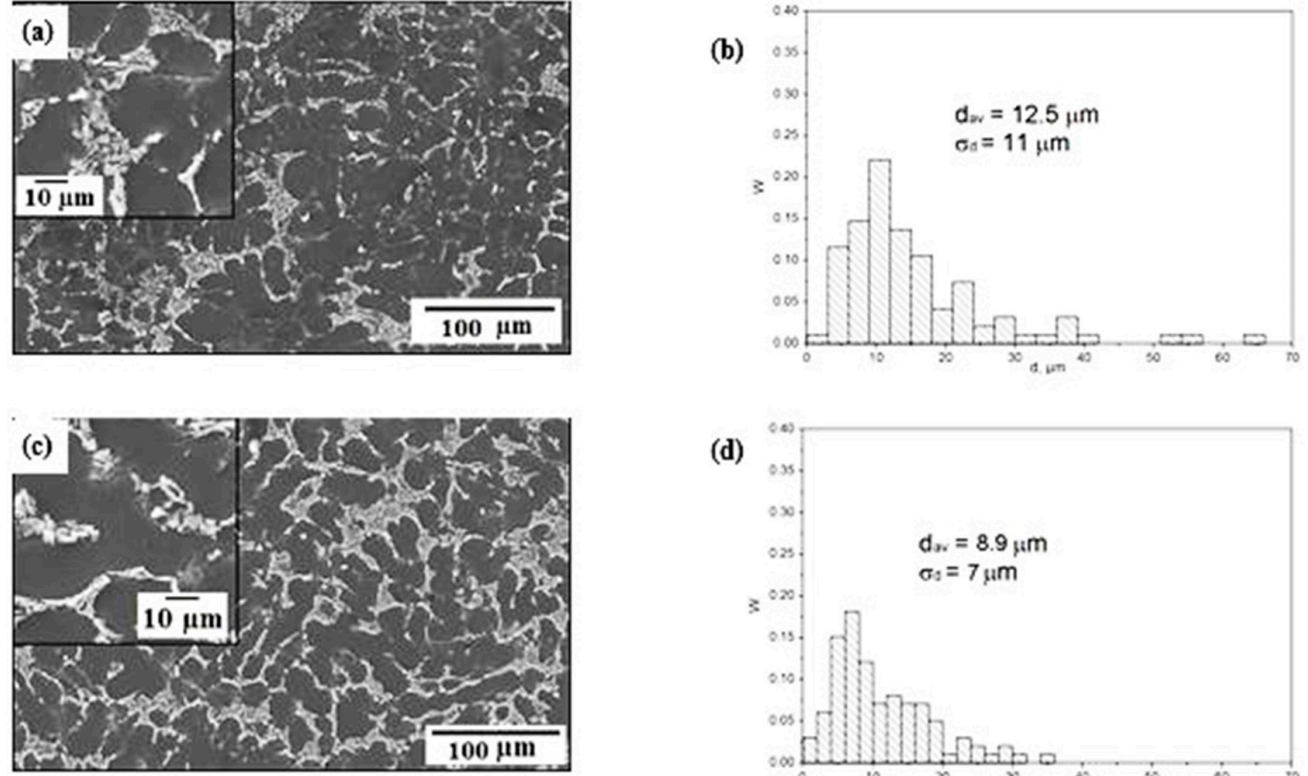

(d)
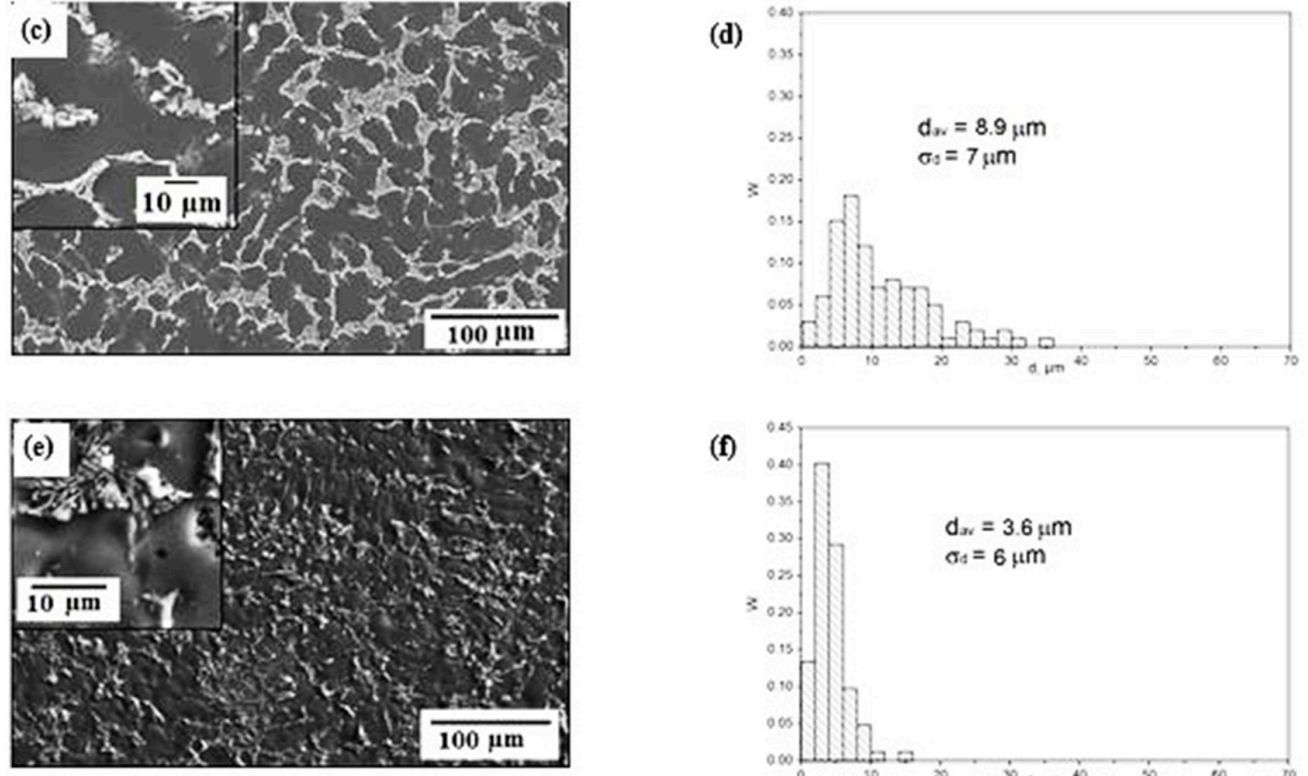

(f)
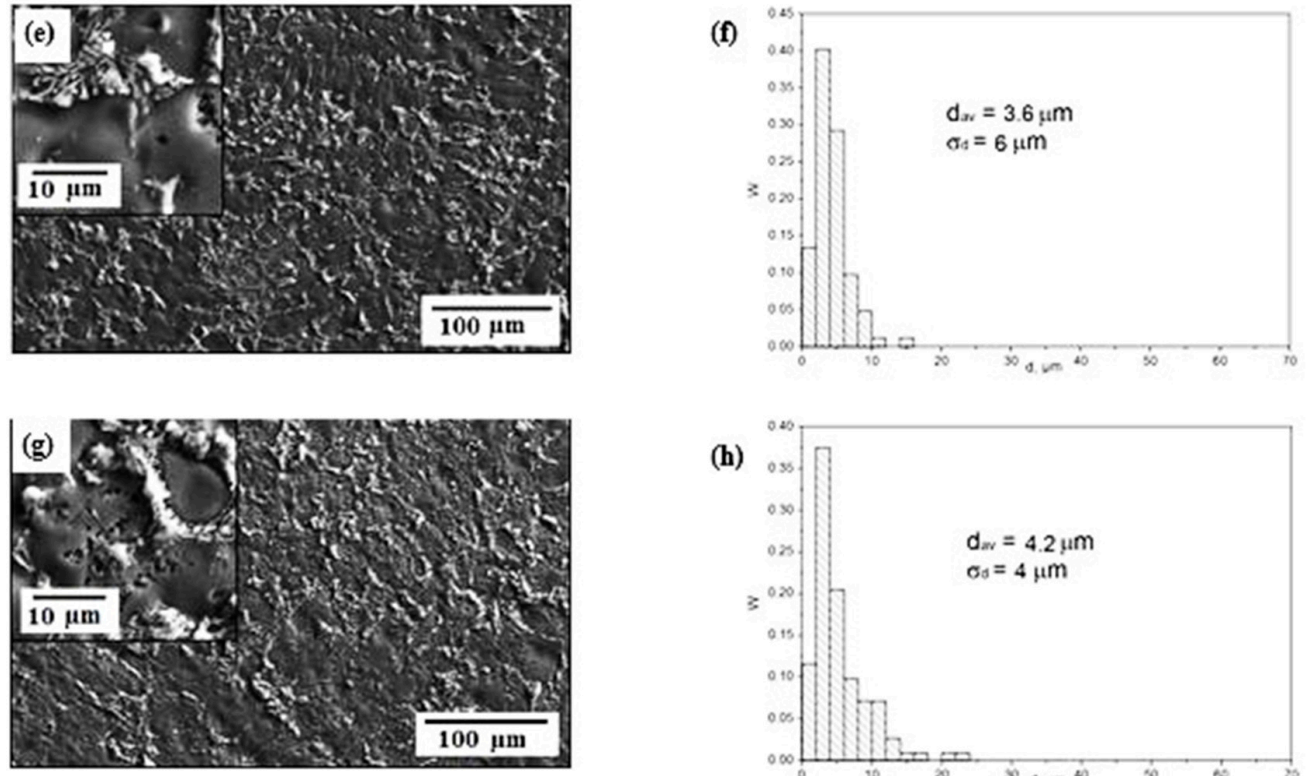

(h)

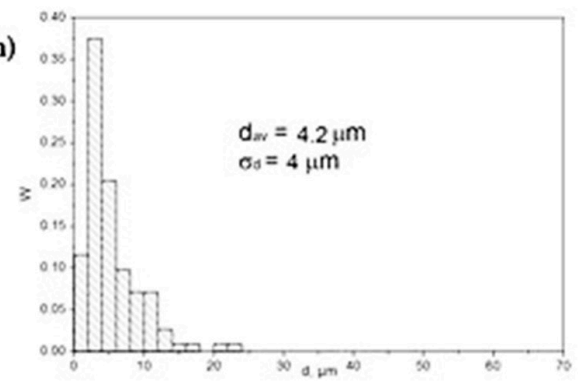

Figure 1. Morphology and a histogram of particles distribution by the sizes of eutectic Si: $(\mathbf{a}, \mathbf{b})$ in the initial alloy; (c,d) supplemented with 0.4 mass. \% Ultrafine powders; (e,f) 0.2 mass. \% $\mathrm{K}_{2} \mathrm{ZrF}_{6}$; (g,h) 0.2 mass. \% Arsal 2120.
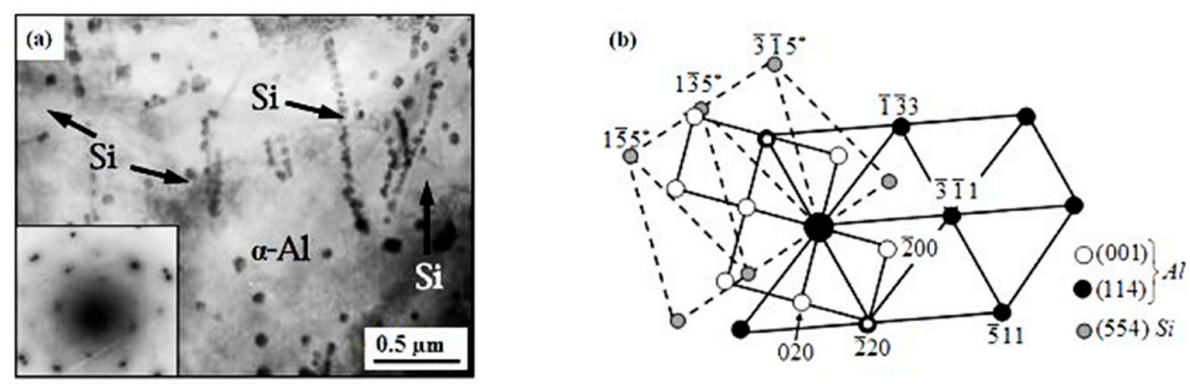

Figure 2. Transmission electron microscopy (TEM) image of the initial Al-7\%Si alloy: (a) a bright-field image and its microdiffraction pattern; (b) an indexed scheme of section (a). 
The introduction of 0.4 mass. \% UFP in the aluminum melt resulted in a more uniform distribution of eutectic throughout the sample section. Note that there was a considerable decrease in the sizes of plate-like eutectic silicon in Figure 1c. As in the initial alloy, eutectic silicon had a needle- or plate-like texture; at that, the range of silicon distribution by sizes was two times less and was $\sim 1.8-36 \mu \mathrm{m}$ (Figure 1d). The average size of Si crystals was $\sim 8.9 \mu \mathrm{m}$, which is considerably less than that of the initial alloy. According to TEM, it was established that apart from plate-like Si particles, as well as in the initial alloy, fine-dispersed particles of secondary Si were present in $\alpha$-Al grains (Figure 3). It was shown that after the introduction of 0.4 mass. \% UFP, they were distributed throughout the volume more uniformly. A conglomeration of Si particles was not observed in Figure 3a. The size of dispersed particles of secondary $\mathrm{Si}$ in $\alpha-\mathrm{Al}$ was $\leq 50 \mathrm{~nm}$, which is substantially less than that in the initial sample. The particles of the Si phase of both eutectic silicon and secondary silicon had a defect-free structure. The formation of the Si plates was described in Reference [15]. The subsequent planar growth of Si crystals straightens the bifilms, thereby creating long straight cracks in association with the primary Si particles. The long Si particles reflect the length of the straightened-out bifilms. The straightened cracks are proposed to be the primary reason for the reduced properties of unmodified alloys. Oxides can lead to the favored growth of substrates, discouraging both particulate and plate-like primary Si in favor of a coral-like growth of eutectic Al-Si at a lower temperature, avoiding the straightening of bifilm cracks and thereby conferring a benefit on mechanical properties [15].
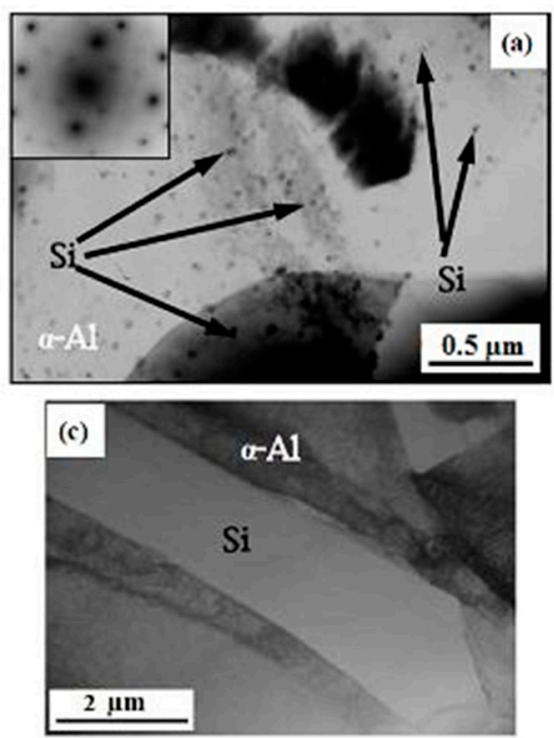

(b)

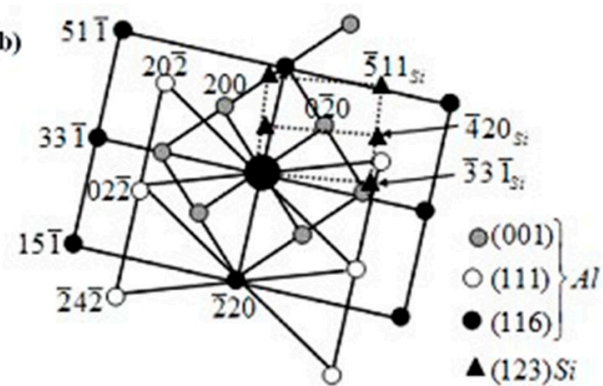

(d)

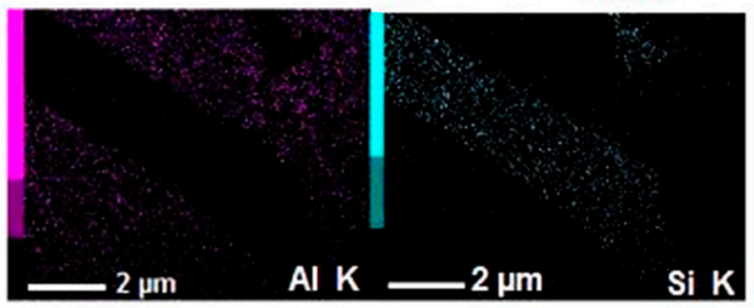

Figure 3. TEM image of the Al-7\%Si alloy after the introduction of 0.4 mass. \% UFP: (a) a bright-field image and its microdiffraction pattern of the section of the $\alpha$-Al grain with precipitations of secondary $\mathrm{Si}$; (b) an indexed scheme of the modifying mixture (MM) of section (a); (c) a bright-field image of the section of the eutectic region containing acicular Si crystals; (d) mapping of section (c).

When 0.2 mass. $\% \mathrm{~K}_{2} \mathrm{ZrF}_{6}$ was introduced into the aluminum melt, there was also a uniform distribution of eutectic $(\alpha-\mathrm{Al}+\mathrm{Si})$ throughout the sample section (Figure 1e). According to SEM data, there was more than a three-fold reduction of the average size of crystals of eutectic Si in the sample supplemented with $\mathrm{K}_{2} \mathrm{ZrF}_{6}$ compared to the initial alloy, as they were $\sim 3.6 \mu \mathrm{m}$ (Figure 1f). The introduction of 0.2 mass. $\% \mathrm{~K}_{2} \mathrm{ZrF}_{6}$ led not only to the decrease in the sizes of Si crystals, but also to a change in their morphology (Figure 4). There was more than a three-fold decrease of the sizes of needle- and/or plate-like Si crystals. 


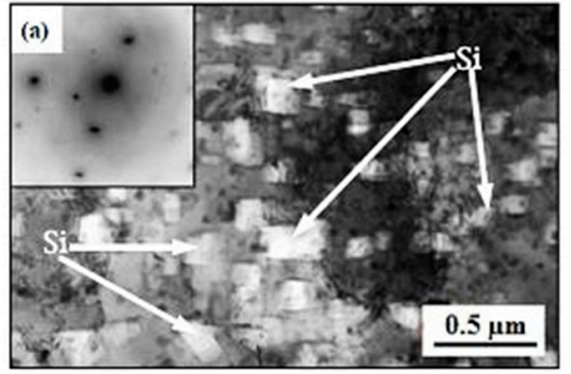

(b)
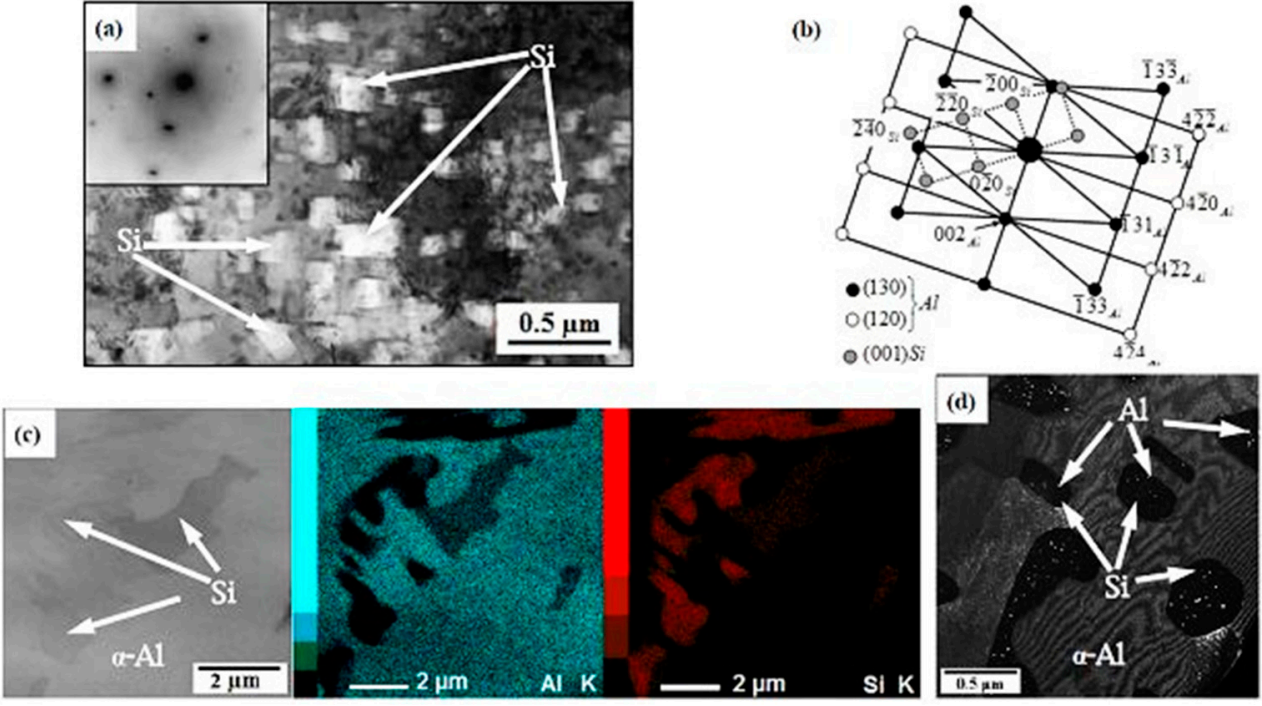

Figure 4. An electron microscope image of the Al-7\%Si alloy after the introduction of 0.2 mass. \% $\mathrm{K}_{2} \mathrm{ZrF}_{6}$ : (a) a bright-field image and its microdiffraction pattern; (b) reflexes belonging to planes (120) and (130) Al and (001) Si are presented; (c) a bright-field image and mapping of the section; (d) a dark-field image.

According to TEM, secondary silicon particles of a different shape formed in the $\alpha$-Al grain. Crystals with a cubic shape and the size of $\sim 0.05-2 \mu \mathrm{m}$ and fine-dispersed particles similar to a spherical shape with the size of $0.008-0.07 \mu \mathrm{m}$ were present in Figure $4 \mathrm{a}$. It is possible to presume that the introduction of modifiers resulted in the local change in the concentration composition of the alloy. Figure $4 \mathrm{~d}$ presents a dark-field TEM image of the modified Al-7\%Si alloy, in which one can see that within coarse Si crystals of $\sim 0.5 \mu \mathrm{m}$, there were $\mathrm{Al}$ nanoparticles of less than $30 \mathrm{~nm}$. These data were justified by energy dispersive analysis and microdiffraction patterns taken of this area. One might suppose that during the cooling of the alloy in a solid state, the concentration of the aluminum sufficient for the precipitation of secondary $\alpha$-Al grains increased locally in the grains of silicon $(\mathrm{Si})$, representing a solid solution of aluminum in silicon. In the region of the eutectic, eutectic silicon precipitates had various geometrical shapes different from an needle- or plate-like one.

During the modification of the Al-7\%Si alloy with the 0.2 mass. \% flux Arsal 2120, the distribution of the sizes of eutectic Si was in the range of $\sim 1-20 \mu \mathrm{m}$; at that, the average size was $d_{a v} \approx 4 \mu \mathrm{m}$ (Figure $1 \mathrm{~h}, \mathrm{j}$ ). As in the case of the modification of 0.2 mass. $\% \mathrm{~K}_{2} \mathrm{ZrF}_{6}$, there was a change in the morphology of Si crystals precipitated in the eutectic region. Si particles in $\alpha$-Al had a cubic shape with a size of $0.04-0.23 \mu \mathrm{m}$ and coarser particles of different geometrical shapes (Figure 5). In the region of the eutectic mixture solidification, there was silicon of a platelet shape. Precipitated silicon wafers had high lattice stresses and were characterized by a high concentration of defects and twins.

From the analysis of the data obtained, it is possible to conclude that all modifying mixtures introduced into the melt reduced the size of silicon wafers in the eutectic mixture and influenced the localization of secondary Si particles in $\alpha$-Al. When introducing 0.4 mass. \% UFP, consisting of $\mathrm{Na}_{3} \mathrm{AlF}_{6}$ $+\mathrm{K}_{2} \mathrm{ZrF}_{6}+\mathrm{TiO}_{2}+\mathrm{ZrO}_{2}$, the morphology of eutectic and secondary Si did not change, but the size of $\mathrm{Si}$ particles was reduced and they were distributed more uniformly throughout the volume. Similar results were observed in Reference [14], where the influence of complex flux $\left(\mathrm{K}_{2} \mathrm{TiF}_{6}+\mathrm{BaCO}_{3}+\mathrm{C}\right)$ on the microstructure of $\mathrm{Al}-7 \% \mathrm{Si}, \mathrm{Al}-9 \% \mathrm{Si}$, and other alloys was demonstrated. The authors demonstrated that treatment with the complex modifying flux led to the refinement of the eutectic $(\alpha-\mathrm{Al}+\mathrm{Si})$, a more uniform distribution and refinement of $\alpha$-Al dendrites, as well as a $72 \%$ reduction of the area of eutectic Si crystals compared to the unmodified alloy [14]. It is necessary to note that metal oxide 
nanoparticles introduced into the melt precipitated in the alloy structure in the form of particles and agglomerates [14]. They can serve as additional stress concentrators.
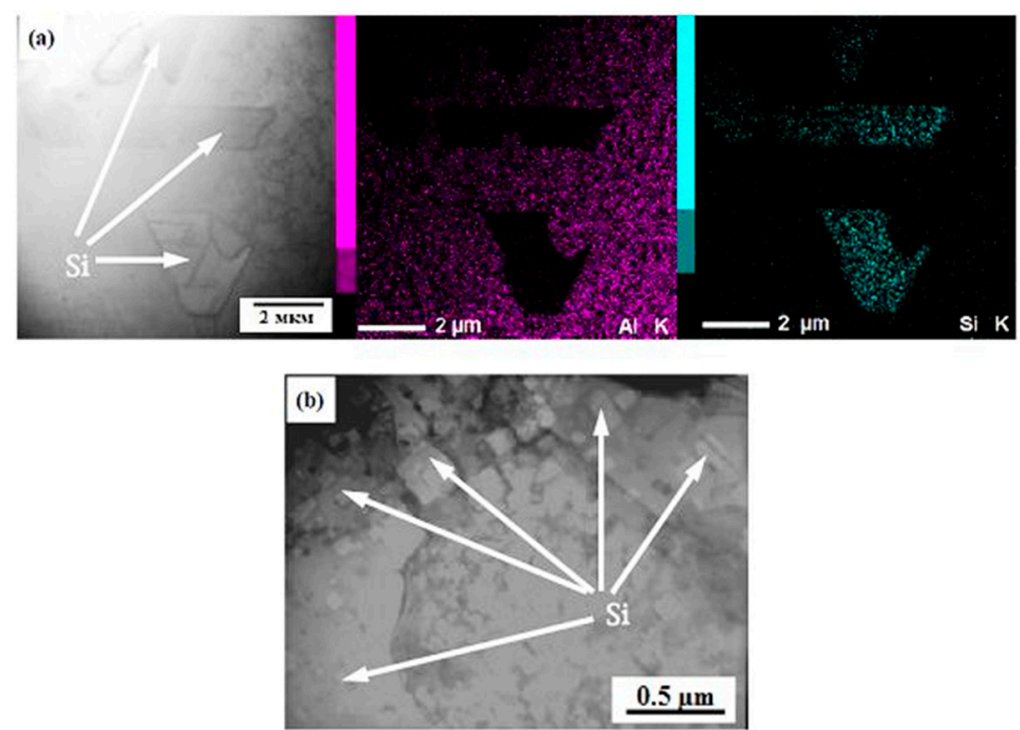

Figure 5. TEM image of the Al-7\%Si alloy with 0.2 mass. \% Arsal 2120: (a) a bright-field image and mapping of the section; (b) a bright-field image.

In our work, it has been shown that when 0.4 mass. \% UFP was introduced into the mixture, the particles were distributed uniformly throughout the volume and assimilated by the melt. By virtue of fluorine-containing salts in the composition of the modifier, a number of chemical reactions, accompanied by a reduction of oxides up to a metallic fine-crystalline state, proceeded. These oxides could be considered as concentrators of grained primary grains and were fully assimilated by the melt. None of the methods (SEM, TEM, XRD) allowed for the detection of these particles. On the other hand, Reference [8] demonstrated that when introducing a hypereutectic composition of $\gamma-\mathrm{Al}_{2} \mathrm{O}_{3}$ particles in the amount of $0.5-1.0 \%$ into the silumin melt, the morphology of coarse wafers of primary $\mathrm{Si}$ with a size of 78-400 $\mu \mathrm{m}$ transformed into a more compact material, containing $41-49 \mu \mathrm{m}$-sized particles of primary $\mathrm{Si}$. In this case, $\gamma-\mathrm{Al}_{2} \mathrm{O}_{3}$ particles were located both in the matrix of the $\alpha$-solid solution and in the primary crystals of $\mathrm{Si}[8]$.

When introducing fluxes ( 0.2 mass. $\% \mathrm{~K}_{2} \mathrm{ZrF}_{6}$ and 0.2 mass. \% Arsal 2120), not only a three-fold refinement of Si occurred, but also a change of its morphology. The particles of eutectic Si acquired a different geometrical shape. In Reference [21] it was demonstrated that, when introducing $\mathrm{Sr}$ and $\mathrm{Na}$ during the casting of eutectic Al-Si alloys, the needle structure of eutectic Si transformed into a fine fibrous one. The achievement of the fine fibrous structure of eutectic Si due to the introduction of modifying agents was observed by others as well [22,23]. The rate of solidification processes and the solidification temperature determined the morphological characteristics of eutectic and secondary grains of silicon as well as a finite structure and, as a consequence, the required properties of alloys.

In Reference [19], it was mentioned that when introducing 0.4 mass. \% UFP to the aluminum melt, a number of chemical reactions having a negative value of $\Delta \mathrm{G}^{\circ} 298$ were thermodynamically possible. One of the possible mechanisms of interaction of the modifier in the melt was reduced to chemical processes of the decomposition of complex salts $\mathrm{K}_{2} \mathrm{ZrF}_{6}$ and $\mathrm{Na}_{3} \mathrm{AlF}_{6}$, accompanied by the formation of fluorides of aluminum, potassium, and sodium, gaseous products, and metallic particles of $\mathrm{Zr}$ and $\mathrm{Ti}$, reduced from oxides. Reduced metallic particles were the solidification centers in the melt. A high negative value of $\Delta G^{\circ} 298$ in chemical reactions showed a high thermodynamic probability of the reactions proceeding. It is known that eutectic solidification represents a growth of crystals of two phases, $\alpha-\mathrm{Al}$ and $\mathrm{Si}$, among which eutectic silicon is the leading phase [2]. Thermal effects of chemical 
reactions, proceeding during the interaction of $\mathrm{MM}$ with the melt, could influence the temperature and the rate of solidification and, correspondingly, the morphology of silicon crystals.

Figure 6 presents the DSC curves of the cooling of the Al-7\%Si alloy both in the initial state and in the state when different modifying mixtures were introduced. It shows that after the introduction of 0.4 mass. \% UFP, the solidification of eutectic Si proceeds at a higher temperature than that for the initial alloy, despite the fact that the liquidus temperature has changed by only $3{ }^{\circ} \mathrm{C}$. According to the differential thermal analysis (DTA) data, a shift in the temperature of the crystallization of the eutectic containing silicon and aluminum crystals was observed. The structural changes during the solidification of eutectic Si were observed: the size of Si wafers decreased 1.5 times, but the morphology remained the same. Similar results were observed in Reference [2], and it was demonstrated that with the increase of the Sm content in the ADC12 alloy, the temperature of the primary solidification changed by $2{ }^{\circ} \mathrm{C}$ each time the agent was added, and the wafers of eutectic Si were refined without alteration of its morphology.

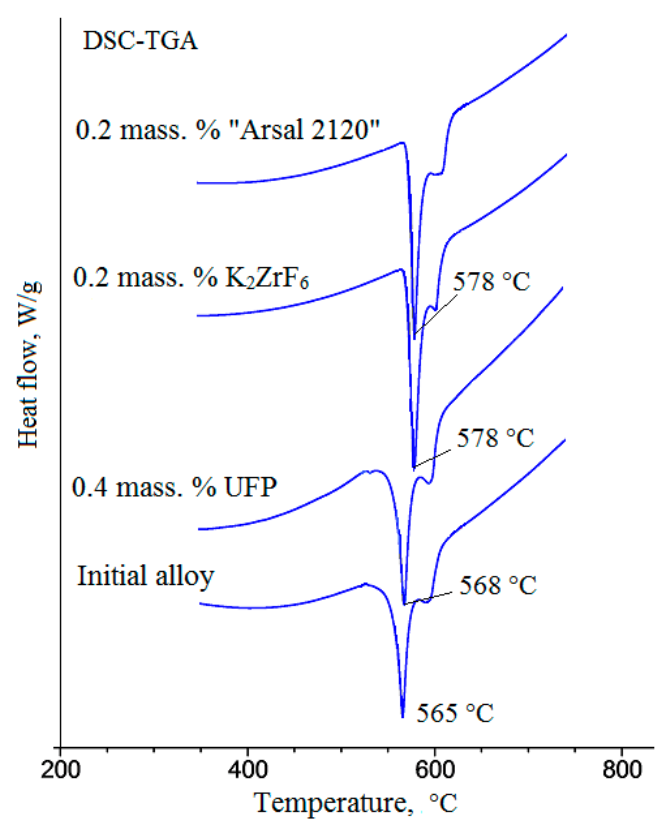

Figure 6. DSC curves of cooling of $\mathrm{Al}-7 \% \mathrm{Si}$ with different modifying compositions at a heating temperature of $10^{\circ} \mathrm{C} / \mathrm{min}$.

After the introduction of fluorine-containing salts in the amount of 0.2 mass. $\% \mathrm{~K}_{2} \mathrm{ZrF}_{6}$ and 0.2 mass. \% Arsal 2120, there was a significant temperature shift of the onset of precipitation of the primary Si crystals into the region of higher temperatures (by $13{ }^{\circ} \mathrm{C}$ ) (Figure 6); DSC curves for $\mathrm{K}_{2} \mathrm{ZrF}_{6}$ and Arsal 2120 virtually coincided. Crystallization at high temperatures was a consequence of supercooling. Such significant supercooling of the Al-7\%Si alloy resulted in primary and eutectic $\mathrm{Si}$ crystals undergoing a three-fold refinement and acquiring different geometric shapes. When fluoride salts were used, there were decomposition processes, accompanied by an intensive thermal effect. The temperature increased in the melt locally, and, correspondingly, the solidification of primary crystals occurred at a higher temperature $\left(573^{\circ} \mathrm{C}\right)$ and was accompanied by rapid solidification from the melt. A modifying mixture containing oxides along with cryolite was more effective for the refinement of structural components of alloys. This was because processes of oxide decomposition were characterized by a less intensive thermal effect, and, as a consequence, the formation of a fine-crystalline structure occurred. As a result of chemical reactions, a multicomponent system with a high concentration of points of the solidification onset of the melt, formed from the products of oxide reduction, was distributed uniformly throughout the volume of the system. The presence of liquid 
fluoride-containing salts enabled a reduction of the surface energy of wetting and, correspondingly, a more uniform distribution of particles - points of solidification - throughout the volume of the melt.

The microstructure and mechanical properties of alloys in the initial state and after the introduction of various additives are presented in detail in References $[16,19]$. It was shown that for all of the modified samples, an increase in the relative elongation was characteristic. However, the temporary tear resistance for all samples varied from $14.4 \mathrm{kgs} / \mathrm{mm}^{2}$ to $22 \mathrm{kgs} / \mathrm{mm}^{2}$. For all of the modified samples, the increase in mechanical properties was due mainly to the decrease in the dimensions of the silicon wafers. However, the uneven distribution of the eutectic and its accumulation in alloys modified by commercial $\mathrm{K}_{2} \mathrm{ZrF}_{6}$ and Arsal 2120 influenced the strength values and the optimal relationship between the structure and mechanical properties. The introduction of MM to the melt led to a secondary liberation of silicon particles from the solid solution, due to which an optimal relationship between the structure and mechanical properties was achieved.

\section{Conclusions}

The influence of the additives of modifying mixtures of a different composition on the features of precipitation of silicon crystals during the cooling of Al-7\%Si alloy was investigated. The formation of two types of silicon crystals has been established. The first type of silicon crystals precipitated during the solidification of the eutectic mixture $(\alpha-\mathrm{Al}+\mathrm{Si})$. In the eutectic region, silicon precipitations predominantly had a needle- or plate-like shape. The second type of silicon crystals precipitated during the secondary solidification out of the solid phase of $\alpha$-Al. When using fluoride-containing salts, there was a temperature rise of the eutectic solidification. Silicon crystals could be coarser in size (up to $10 \mu \mathrm{m}$ ), accompanied by local excess of the aluminum concentration. In these crystals, the local excess of the concentration and precipitation of $\alpha$-Al grains from silicon crystals was possible. Hence, the modifying mixtures introduced to the melt influenced the temperature and the rate of solidification processes as well as the shape and localization of precipitated silicon crystals.

Acknowledgments: The research was performed under a grant of Russian Science Foundation (project No. 17-13-01252).

Author Contributions: Anna Zykova wrote the paper; Kazantseva Lyudmila measured the dimensions of the eutectic Si and plotted a histogram of the eutectic Si particle size distribution; Natalya Popova conducted research on transmission electron microscopy; Alexander Vorozhtsov and Irina Kurzina managed the experimental work and made correction on the article.

Conflicts of Interest: The authors declare no conflict of interest.

\section{References}

1. Livshits, B.G.; Kraposhin, V.S.; Linetsky, Z. Physical Properties of Metals and Alloys, 2nd ed.; Metallurgy: Moscow, Russia, 1980.

2. Rao, Y.; Yan, H.; Hu, Z. Modification of eutectic silicon and $\beta-\mathrm{Al}_{5} \mathrm{FeSi}$ phasesin as-castADC12 alloys by using samarium addition. J. Rare Earths 2013, 31, 916-922. [CrossRef]

3. Chen, C.; Liu, Z.; Ren, B.; Wang, M.; Weng, Y.; Liu, Z. Influences of complex modification of P and RE on microstructure and mechanical properties of hypereutectic Al-20Si alloy. Trans. Nonferrous Met. Soc. China 2007, 17, 301-306. [CrossRef]

4. Zeren, M.; Karakulak, E. Influence of Ti addition on the microstructure and hardness properties of near-eutectic Al-Si alloys. J. Alloys Compd. 2008, 450, 255-259. [CrossRef]

5. Li, J.H.; Wang, X.D.; Ludwig, T.H.; Tsunekawa, Y.; Arnberg, L.; Jiang, J.Z.; Schumacher, P. Modification of eutectic Si in Al-Si alloys with Eu addition. Acta Mater. 2015, 84, 153-163. [CrossRef]

6. Chernega, D.F.; Mogilatenko, V.G. Influence of dispersed refractory particles in the melt in the solidification of aluminum and silumin. Foundry 2002, 12, 6-8.

7. Dahle, A.K.; Nogita, K.; McDonald, S.D.; Dinnis, C.; Lu, L. Eutectic modification and microstructure development in Al-Si Alloys. Mater. Sci. Eng. A 2005, 413-414, 243-248. [CrossRef] 
8. Li, Q.; Xia, T.; Lan, Y.; Zhao, W.; Fan, L.; Li, P. Effect of in situ $\gamma-\mathrm{Al}_{2} \mathrm{O}_{3}$ particles on the microstructure of hypereutectic Al-20\%Si alloy. J. Alloys Compd. 2013, 577, 232-236. [CrossRef]

9. El-Mahallawi, I.S.; Shash, A.Y.; Amer, A.E. Nanoreinforced cast Al-Si alloys with $\mathrm{Al}_{2} \mathrm{O}_{3}, \mathrm{TiO}_{2}$ and $\mathrm{ZrO}_{2}$ nanoparticles. Metals 2015, 5, 802-821. [CrossRef]

10. Molina, C.M.; Valdes, A.F.; Valdez, R.M.; Torres, J.T.; Rosales, N.R.; Estrada, R.G. Modification of Al-Si alloys by metallothermic reduction using submerged SrO powders injection. Mater. Lett. 2009, 63, 815-818. [CrossRef]

11. Wang, K.; Jiang, H.Y.; Jia, Y.W.; Zhou, H.; Wang, Q.D.; Ye, B.; Ding, W.J. Nanoparticle-inhibited growth of primary aluminium in Al-10Si alloys. Acta Mater. 2016, 103, 252-263. [CrossRef]

12. Nowak, M.; Bolzoni, L.; HariBabu, N. The effect of Nb-B inoculation on binary hypereutectic and neareutectic LM13 Al-Si cast alloys. J. Alloys Compd. 2015, 641, 22-29. [CrossRef]

13. Mohanty, P.S.; Gruzleski, J.E. Mechanism of grain refinement in aluminium. Acta Metall. Mater. 1995, 43, 2001-2012. [CrossRef]

14. Petrov, I.A.; Ryakhovsky, A.P.; Moiseev, V.S.; Bobryshev, B.L.; Shlyaptseva, A.D. Prospects for the use of carbon-containing material for the processing of silumin. Foundry Russ. 2016, 1, 28-32.

15. Campbell, J.; Tiryakioğlu, M. Review of effect of P and Sr on modification and porosity development in Al-Si alloys. J. Mater. Sci. Technol. 2010, 26, 262-268. [CrossRef]

16. Matsuura, K.; Kudoh, M.; Kinoshita, H.; Takahashi, H. Precipitation of Si particles in a super-rapidly solidified Al-Si hypereutectic alloy. Mater. Chem. Phys. 2003, 81, 393-395. [CrossRef]

17. Zykova, A.P.; Kazantseva, L.A.; Kurzina, I.A.; Dammer, V.K.; Chumaevaskii, A.V. Influence of the modifying ability of various compositions on the microstructure and properties of the AK7ch alloy. Russ. J. Non-Ferrous Met. 2015, 56, 593-598. [CrossRef]

18. SCHÄFER Metallurgie GmbH. Available online: http://www.schaefer-metallurgie.com/arsal-2120-kg/ (accessed on 29 January 2018).

19. Zykova, A.P.; Kazantseva, L.A.; Kurzina, I.A. The effect of ultra-fine powders on the structural formation processes and mechanical properties of Al-7\%Si alloy. AIP Conf. Proc. 2016, 1772, 030020.

20. GOST 1583-93. Aluminium Foundry Alloys; Technical Specifications; Aluminium Foundries. Technical Conditions; Publishing House of Standards: Moscow, Russia, 2003.

21. Lu, L.; Nogita, K.; Dahle, A.K. Combining Sr and Na additions in hypoeutectic Al-Si foundry alloys. Mater. Sci. Eng. A 2005, 399, 244-253. [CrossRef]

22. Xing, P.F.; Gao, B.; Zhuang, Y.X.; Liu, K.H.; Tu, G.F. Effect of erbium on properties and microstructure of Al-Si eutectic alloy. J. Rare Earths 2010, 28, 927-930. [CrossRef]

23. Huang, X.; Yan, H. Effect of trace La addition on the microstructures and mechanical property of as-cast ADC12Al-alloy. J. Wuhan Univ. Technol.-Mater. Sci. 2013, 28, 202-205. [CrossRef] 